\title{
Effect of Wet Granulation Technique on Preparation and Characterization of Piroxicam Inclusion Complexation
}

\author{
Authors \& Affiliation: \\ Looi Shu Ying', \\ Mahibub Muhamadsa Kanakal*1, \\ Noor Shahida Binti Ajmi ${ }^{3}$, \\ Vijay Kumar Methi ${ }^{1}$, \\ Rabia Basharat ${ }^{2}$, \\ Lean Yen Loong ${ }^{2}$ \\ ${ }^{I}$ Department of Pharmaceutics and \\ Pharmaceutical Technology, Faculty \\ of Pharmacy, Quest International \\ University, 30250, Ipoh, Perak \\ Darul Ridzuan, Malaysia \\ ${ }^{2}$ Department of Pharmaceutical \\ Chemistry, Faculty of Pharmacy, \\ Quest International University, \\ 30250, Ipoh, Perak Darul Ridzuan, \\ Malaysia \\ ${ }^{3}$ Laboratory Division, Quest \\ International University, 30250, \\ Ipoh, Perak Darul Ridzuan, \\ Malaysia.
}

\section{Corresponding Author}

\section{Mahibub Muhamadsa Kanakal}

Received on: 28.08.2020

Accepted on: 03.12.2020

(C) 2020.The Authors. Published under Caribbean Journal of Science and Technology

ISSN 0799-3757

\section{http://caribjscitech.com/}

\begin{abstract}
:
The preparation of any pharmaceutical drug delivery system requires solubility as one of the top most requirements for active pharmaceutical ingredients. Inclusion Complexation has become popular in formulation development of water poor soluble active ingredients. In current study we have selected water poor soluble drug Piroxicam (PX) as the model active pharmaceutical ingredient. To release piroxicam drug from solid dosage forms such as tablets and capsules it requires improvement in its solubility prior to preparation of final dosage form. For large scale production and commercialization process solubility enhancement procedures must be simple, economical and reproducible at different batch size. Objective of this study is to study effect of wet granulation on the complexation of beta-cyclodextrin with Piroxicam using Fourier transform infrared spectroscopy (FT-IR) and X-ray Diffraction and Scanning Electron Microscopic analysis. Inclusion Complex was prepared using betaCyclodextrin (BCD) by wet granulation technique. Molecular dispersion prepared was characterized by FTIR, XRD, Phase Solubility and Dissolution Studies. The result confirmed with SEM, XRD and FTIR for formation of Complexation of PX and $\mathrm{BCD}$ and increase in solubility was noticed with increase in concentration of complexing agent $\mathrm{BCD}$. Inclusion complexation is very useful and effective strategy to adopt for further improve the solubility along with wet granulation technique. The approach to enhance the solubility becomes more practical and reproducible in industry and commercialization due to well established machines and production procedures for wet granulation technique to form inclusion complex for water poor soluble drugs.
\end{abstract}

Keywords: Wet granulation, Beta-cyclodextrin, Piroxicam, Complexation, Solubility 


\section{Introduction:}

Piroxicam (PX) is drug of non-steroidal anti-inflammatory category (NSAIDs). PX as active pharmaceutical ingredient is an analgesic and an anti-inflammatory drug. Pharmacologically this drug inhibits the synthesis of prostaglandins. COX-I and COX-II are cyclo-oxygenase enzymes that are principally crucial for the creation of prostaglandins, which are essential for supporting a healthy gastrointestinal tract, renal functioning, platelet operate effectively, and other typical functions. COX-2 is a kind of enzyme that is activated and responsible for the production of prostaglandins, which are key mediators of inflammation, pain, and fever. PX inhibits and COX-2 and hence prostaglandins further to provide comfort against pain inflammation. ${ }^{1}$ Piroxicam is one of the potent prescribed NSAIDs for the treatment of inflammation, pain, and stiffness triggered through osteoarthritis and rheumatoid arthritis ${ }^{2}$.

Physicochemical property of PX is poorly soluble in water and needs enhancement of solubility by adjuvant or suitable technique to improve its solubility in water. Because of its capacity to produce molecular dispersion with a wide range of poorly soluble pharmaceuticals, inclusion complexation is a significant solubility improving technology in the pharmaceutical industry. Complexation improves the physicochemical characteristics of the guest molecule, such as higher solubility, faster dissolving rate, and stability ${ }^{3}$.

Inclusion complexes are chemical structures with the addict-like structure of one host molecule physically enclosing another. The encapsulated guest molecule is located in the host cavity without changing the host framework structure considerably. Many methods have been utilized to prepare cyclodextrin complexes such as coprecipitation, kneading and dry mixing preparation. $\beta$-cyclodextrin has the capacity to form inclusion complexes with different types of molecules. As a result, the formation of complexes is influenced by a number of parameters, including the interaction between the model drug and cyclodextrin, as well as the solvent utilized ${ }^{4}$.

Various characterization techniques are used to evaluate formation of complexation such as Fourier transform spectroscopy, X-ray Diffraction analysis, Scanning electron microscope Images and phase solubility studies ${ }^{5}$.

Wet granulation is well known and well established in pharmaceutical industries for manufacturing of granules which can be further used to produce tablets, capsules and sachet. Wet granulation method involves imparting mechanical strength via solvents, binders and other excipients after evaporation of solvent used for granulation ${ }^{6}$. Inclusion complexation is very useful and effective strategy to adopt for further improve the solubility along with wet granulation technique. The approach to enhance the solubility becomes more practical and reproducible in industry and commercialization due to well established machines and production procedures for wet granulation technique to form inclusion complex.

However wet granulation is was not explored to understand inclusion complexaation formation of PX with beta cyclodextrin using wet granulation method. Current study objective is to investigates effect of wet granulation technique on formation of Piroxicam inclusion complex.

\section{Materials:}

The following chemicals were Piroxicam, $\beta$-Cyclodextrin, Potassium Dehydrogenase Phosphate, Di-Sodium hydrogen Phosphate, Sodium Chloride and Concentrated Hydrochloride Acid.

\section{Methods:}

\section{Preformulations Studies of Powder:}

Preformulation investigations are the initial phase in the rational creation of a pharmacological substance's dosage form, and they are described as an assessment of a pharmaceutical substance's physical chemical qualities alone and when mixed with excipients ${ }^{7,10}$.

\section{Piroxicam $\beta$-Cyclodextrin Inclusion Complex:}

PX along with $\beta$-Cyclodextrin are weighted respectively with the ratio of 1: 1.5. The combination of the complex which is equivalent to 500mg PX is prepared by wet granulation with $1 \mathrm{ml}$ aqueous $50 \%$ ethanol, in a glass mortar. The mass then was dried in a hot air oven set of not more than 50 degrees Celsius. The dry mass of PX-HC was again desiccated overnight utilizing sodium hypochlorite being the desiccant ${ }^{8,10}$. 


\section{Phase Solubility Study (Ks):}

Solubility measurements were performed according to Higuchi and Connors et. al. ${ }^{16}$ Excess PX (0.05g) was mixed to $20 \mathrm{ml}$ of water or an aqueous phase of CDs (concentration ranged $0.003-0.015 \mathrm{M}$ ) and agitated at $251^{\circ} \mathrm{C}$. After 3 days of equilibrium, aliquots were taken, filtered $(0.45 \mathrm{~m})$, and spectrophotometrically tested for amount of drug at $355 \mathrm{~nm}$. Based with the following expression, the apparent binding constants, the stability constant (Ks), were determined from the slope as well as intercept of the straight lines of the phase solubility graphs: ${ }^{8,10}$

$\mathrm{Ks}=$ slope $\mathrm{S}_{0}(1$-slope $)$

\section{Fourier-Transform Infrared Spectroscopy (FTIR):}

The samples of $\mathrm{PX}, \beta-\mathrm{CD}$, and piroxicam- $\beta$-CD in their complex had already being pulverized and well mixed with $\mathrm{KBr}$ and dried at temperature $50{ }^{\circ} \mathrm{C}$ for 2 hours. The $\mathrm{KBr}$ disks were prepared by compressing the powder and evaluated by FTIR absorption spectral analysis ${ }^{9-13}$.

\section{X-ray Diffractometry (XRD):}

With Ni-filled $\mathrm{Cu}-\mathrm{K}$ radiation and a goniometer velocity of $0.05^{\circ} /$ rain, X-ray diffractograms were acquired in a SimensKristalloflex diffractometer D-500. Having to scrape the tablet surface and placing the powder in the diffractometer cell yielded an X-ray diffractogram ${ }^{9-13}$.

\section{Scanning Electron Microscopy (SEM):}

Ion sputtering was used to cover powder samples with gold at 50mA for 120 second. Gold-coated samples were evaluated ${ }^{9-13}$.

\section{Angle of Repose:}

A funnel approach was used to calculate the angle of repose $(\alpha)$. The mixture was put into a funnel that could be lifted vertically until it reached its maximum cone height (h). The heap's radius (r) was measured, and the angle of repose then computed as follows: $\alpha=\tan -1(\mathrm{~h} / \mathrm{r})^{15}$.

\section{Bulk Density:}

The apparent "Bulk Density" ( $\rho b)$ was calculated by measuring the volume $(\mathrm{Vb})$ \& weight $(\mathrm{M})$ of a presieved pharmaceutical excipients mix in a calibrated cylinder "as it is" $\rho b=M / V b^{15}$.

\section{Hausner's Ratio:}

The Hausner's ratio is a measure of the ease with which powder flows; it is determined utilizing the preceding formula:

Hausner's ratio $=\rho t \backslash \rho b$

Where, ' $\rho b$ ' means Untapped bulk density and ' $\rho t$ ' means Tapped density ${ }^{15}$.

\section{Carr's Index:}

Compressibility is the easiest technique to quantify a powder's free flow attribute; it gives an indicator of how easily a material may be induced to flow and is evaluated as described in the following:

$\mathrm{C}=(\rho \mathrm{t}-\rho \mathrm{b}) / \rho \mathrm{t} \times 100$

Where, ' $\rho b$ ' means Untapped bulk density and ' $\rho t$ ' means Tapped density ${ }^{15}$.

\section{In-vitro Drug Release Analysis:}

The USP Dissolution Testing Equipment Type II, i.e., basket type, was used to quantify the rate of PX release from granules. At the start of each experiment, granules had first been mixed into an empty hard gelatin capsule of dimension $\# 0$ and then put in a dry basket. The dissolving test was done using $900 \mathrm{ml}$ of phosphate buffer $\mathrm{pH} \mathrm{1.2,} \mathrm{at}$ $37^{\circ} \mathrm{C}$ as well as $50 \mathrm{rpm}$, with the basket lowered in the dissolution media and the apparatus running at $50 \mathrm{rpm}$. For 
45 minutes, $5 \mathrm{ml}$ were removed at five-minute intervals. This was kept at 37 degrees Celsius and added to the mass. Absorbance of these solutions was measured using UV Spectrometer. ${ }^{24}$

\section{Results and Discussion:}

\section{Physicochemical properties of Inclusion complex:}

Piroxicam $\beta$-Cyclodextrin Inclusion Complex: Piroxicam has a very poor solubility and to improve the solubility, Piroxicam- $\beta$-cyclodextrin complex with the ratio of $1: 1.5$ were prepared by wet granulation method. All Physicochemical properties of granules were tabulated in Table 1, and all properties are within acceptable range for further process of solid dosage forms as per British Pharmacopeia standards. After wet granulation and drying the color of granules was found light yellowish in color.

\section{Phase Solubility Study:}

The phase solubility graph obtained for $\beta$-cyclodextrin as shown in Figure 1. The shape of the graph showed an AL type system. The apparent stability constant Ks, was calculated. An increase in solubility was noticed with an increase in the ratio of beta cyclodextrin.

\section{Phase Solubility Studies:}

\section{Phase Solubility Studies of Piroxicam and $\beta$-cyclodextrin}

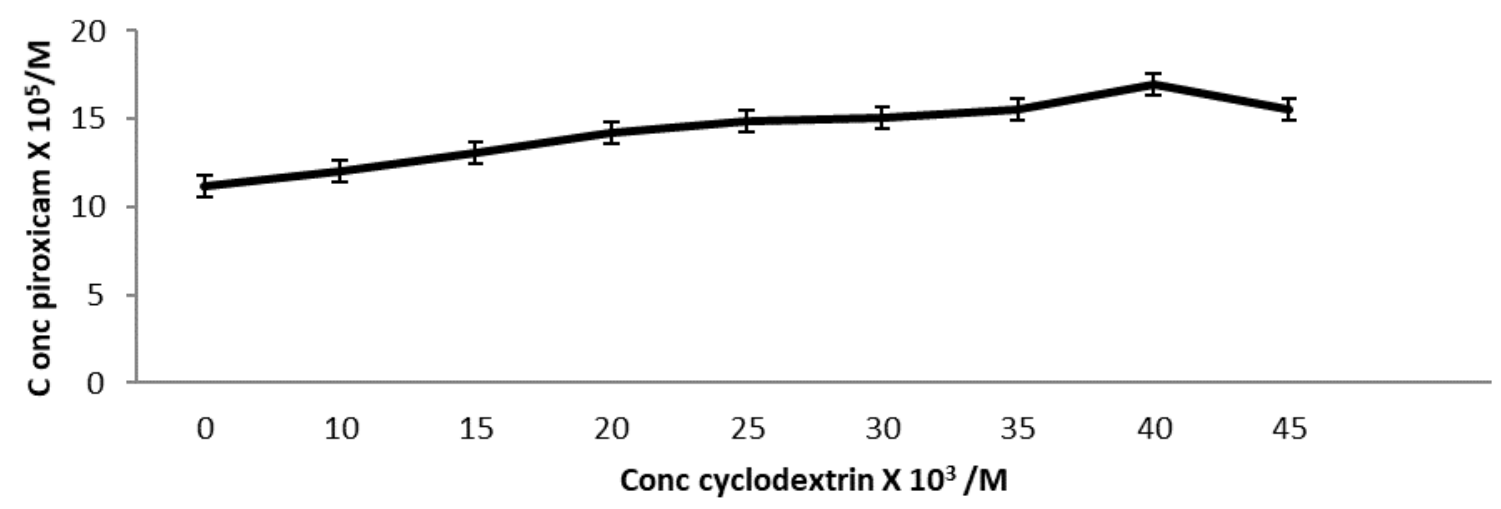

Figure 1: Phase Solubility Study of piroxicam and cyclodextrin

\section{Fourier-transform infrared spectroscopy (FT-IR):}

The FTIR spectra are presented in Figure. 2. Piroxicam spectra showed the band at $3330 \mathrm{~cm}-1$. Their IR spectra just showed slight differences. However, the bands of $-\mathrm{NH}$ and $-\mathrm{OH}$ stretching lie at $3330 \mathrm{~cm}-1$.

\section{X-ray diffractometry (XRD):}

XRPD is a method to determine the molecular state of a complex. Figure 3 depict the diffraction patterns of Piroxicam and $\beta$-cyclodextrin. The X-ray spectrum of the intact Piroxicam shows many sharp reflections, with full width and half height, which indicate its high degree of crystallinity. The $\beta$-cyclodextrin is practically an amorphous material; its spectrum does not contain any peaks that show in Figure 3(B). The inclusion complex Figure 3(C) shows an amorphous pattern from the diffractogram, where the sharp diffraction peaks of Piroxicam disappeared. 


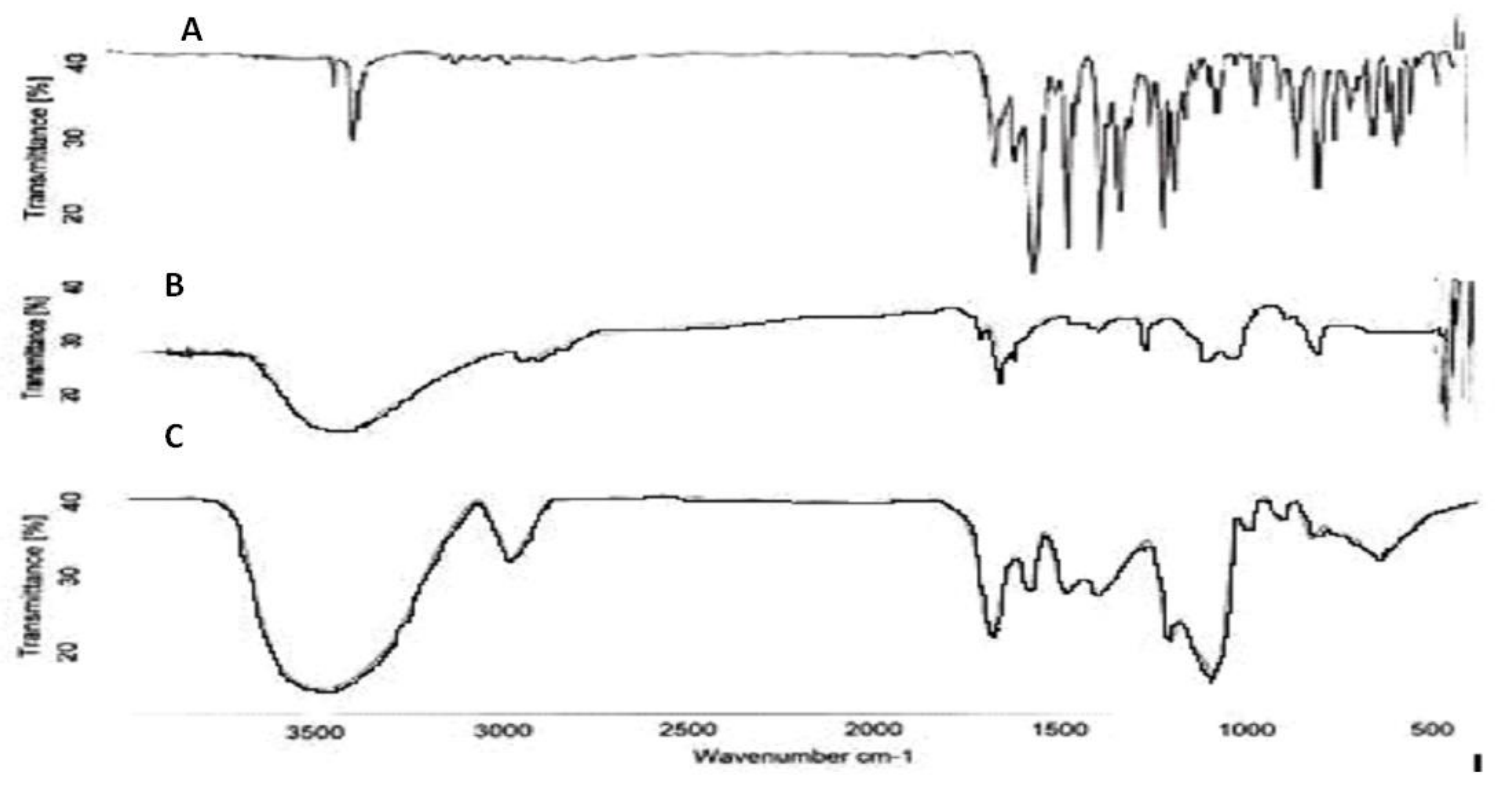

Figure 2:FTIR spectra of Pure Piroxicam (A), Pure $\beta$-cyclodextrin (B) and Piroxicam: $\beta$-cyclodextrin inclusion complex $(\mathrm{C})$

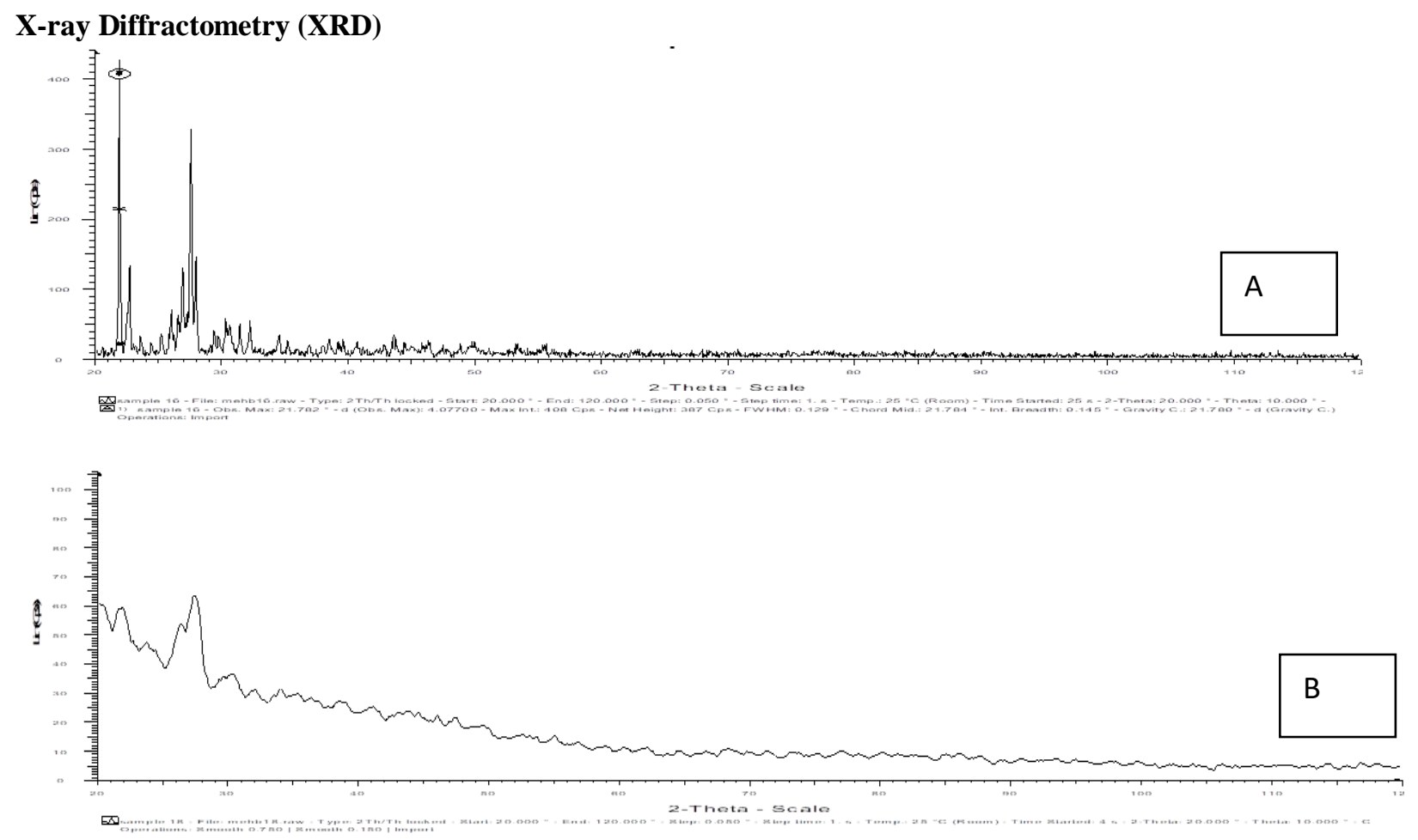




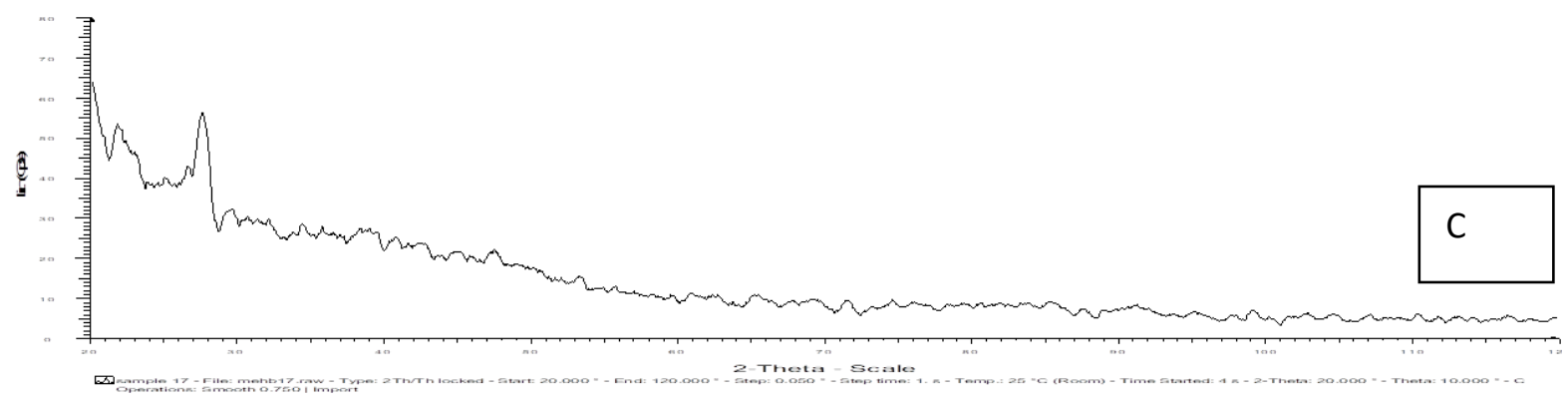

Figure 3: X-ray powder diffractometry of Pure Piroxicam (A), Pure $\beta$-cyclodextrin (B) and Piroxicam: $\beta$ cyclodextrin inclusion complex $(\mathrm{C})$.

\section{Scanning electron microscopy (SEM):}

From SEM analysis, photographs of Piroxicam, $\beta$-Cyclodextrin, and their inclusion complex are shown in Figure 4. PX shows more crystalline (Figure 4(A), and the typical structure of $\beta$-Cyclodextrin seemed as amorphous structures in Figure 4(B). For the inclusion complex, the unique morphology of PX had gone; Figure 4 (C) depicted the inclusion complex as homogenous plus amorphous. The results indicate the formation of an inclusion complex between Piroxicam and $\beta$-Cyclodextrin. The findings show that PX and $\beta$-Cyclodextrin create an inclusion complex.

\section{Scanning Electron Microscopy (SEM)}
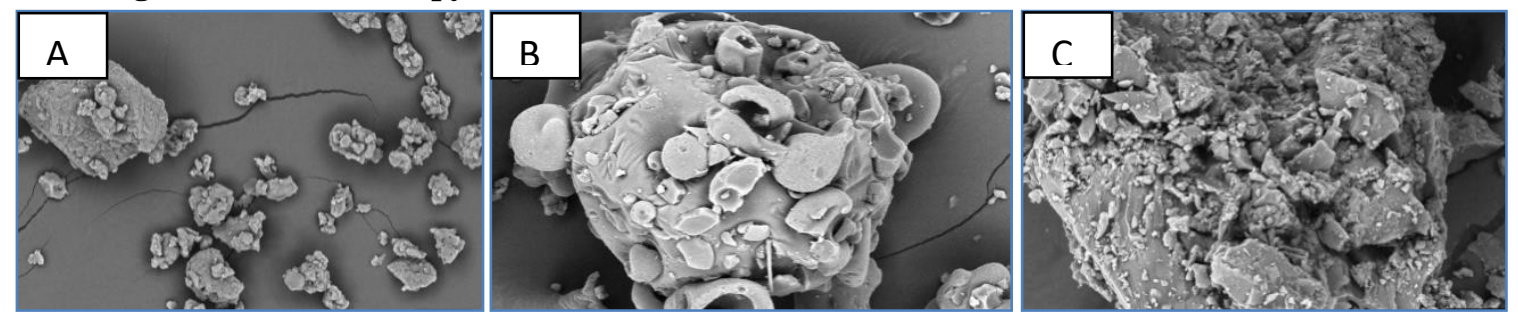

Figure 4: SEM of Pure Piroxicam (A), Pure $\beta$-cyclodextrin (B) and Piroxicam: $\beta$-cyclodextrin inclusion complex $(\mathrm{C})$

\section{Physicochemical Properties Evaluation of Inclusion Complex:}

The angle of repose was found to be in the range of $34.69^{\circ}$ and $36.15^{\circ}$. Bulk density was found to be between 0.237 and $0.257 \mathrm{gm} / \mathrm{cm} 3$ and tapped density between 0.287 and $0.0 .287 \mathrm{gm} / \mathrm{cm} 3$ for the formulations. Hausner's ratio was found to be between 1.14 and 1.16. The result was shown in Table 1. This indicates the granule powder prepared with inclusion complexation possesses required satisfactory physicochemical properties with respect to the flow and density. With these properties of granule powders handling for further process of making tablets and capsules is convenient.

Table 1:Physicochemical properties of inclusion complex $(\mathrm{N}=6)$

\begin{tabular}{|c|c|c|c|c|c|}
\hline No. & $\begin{array}{c}\text { Carr's } \\
\text { index }\end{array}$ & $\begin{array}{c}\text { Angle of } \\
\text { repose } \boldsymbol{\theta}\end{array}$ & $\begin{array}{c}\text { Tapped } \\
\text { Density }\end{array}$ & $\begin{array}{c}\text { Bulk } \\
\text { Density }\end{array}$ & $\begin{array}{c}\text { Hausner } \\
\text { ratio }\end{array}$ \\
\hline 1 & 10.45 & 34.99 & 0.287 & 0.257 & 1.12 \\
\hline 2 & 11.72 & 36.15 & 0.290 & 0.256 & 1.13 \\
\hline 3 & 11.84 & 34.69 & 0.287 & 0.253 & 1.13 \\
\hline 4 & 11.81 & 35.78 & 0.288 & 0.254 & 1.14 \\
\hline 5 & 10.72 & 34.98 & 0.289 & 0.258 & 1.12 \\
\hline 6 & 11.76 & 35.12 & 0.289 & 0.255 & 1.13 \\
\hline
\end{tabular}




\section{Evaluation Drug Release Dissolution of Inclusion Complex in Capsule:}

Six samples were chosen randomly to carry out the evaluation. The weight variations for the capsules were in between the ranges of $195 \mathrm{mg}$ to $197 \mathrm{mg}$. The drug content uniformity concentration is in the range of $88.32 \%$ and $90.17 \%$. The disintegration time for hard gelatin capsules was found to be in the range of 20 to 27 minutes. The percentage drug content of all the optimized formulations was found to be in between $98.32 \%$ to $99.38 \%$ which was within the acceptable limits as per British Pharmacopoeia ${ }^{15}$. The results of disintegration time, drug content and invitro drug release were shown in Table 2. The result showed that the capsules were able to disintegrate within 30 minutes and the dissolution of the capsules showed that almost $95 \%$ of the drug had been released within 45 minutes. This indicates successful drug release of drug from an conventional solid dosage forms which further can be improved with addition other excipients. As such wet granules were filled after drying them into a hard gelatin capsule. We granulation method can be used and suitable to enhance the solubility of Piroxicam using Inclusion Complexation principle by simple granulation technique and saving valuable time multi process technique compared to freeze drying methods which are time consuming and expensive. Wet granulation technique is which is well established and well accepted commercially in pharmaceutical industries.

Table 2:Dissolution (\% of drug released at 45 minutes) $(\mathrm{N}=6)$

\begin{tabular}{|c|c|c|c|c|}
\hline Sample & $\begin{array}{c}\text { Weight } \\
\text { variation }(\mathbf{m g})\end{array}$ & $\begin{array}{c}\text { Drug uniformity } \\
\text { (abs) }\end{array}$ & $\begin{array}{c}\text { Disintegration } \\
\text { (mins) }\end{array}$ & $\begin{array}{c}\text { Dissolution } \\
\mathbf{( \% )}\end{array}$ \\
\hline 1 & 196 & 0.9017 & 20 & 99.75 \\
\hline 2 & 195 & 0.8932 & 27 & 99.81 \\
\hline 3 & 196 & 0.8871 & 25 & 99.77 \\
\hline 4 & 197 & 0.8988 & 23 & 99.70 \\
\hline 5 & 197 & 0.8953 & 23 & 99.74 \\
\hline 6 & 196 & 0.8832 & 26 & 99.75 \\
\hline
\end{tabular}

\section{Conclusion:}

Piroxicam inclusion complex with bet cyclodextrin by wet granulation technique is a useful combination approach to enhance solubility of water poor soluble drug.Enhancement of solubility can be achieved without additional steps and procedures and by incorporating routine wet granulation method. Therefore, the piroxicam inclusion complex formation can be economical and practically adoptable for commercialization without any specialized instrumentation and machines requirements.

\section{Acknowledgement:}

The authors are grateful to the management and staff of the Department of Pharmaceutics and Pharmaceutical Technology, Faculty of Pharmacy, Quest International University (QIU), Ipoh, Perak DarulRidzuan, Malaysia for providing opportunity and financial aid to carry out this research project.

\section{References:}

1. Robertson, E. (2008) Piroxicam xPharm: The Comprehensive Pharmacology Reference. Ed. Enna, SJ., \&Bylund, DB, 1,1-6.

2. Chen, H., Wang, C., Liu, S., \& Sun, C. C. (2020). Development of piroxicam mini-tablets enabled by spherical cocrystallization. Int. J. Pharmaceu, 590: 119953.

3. Banchero, M., Manna, L. (2011). Investigation of the piroxicam/hydroxypropyl- $\beta$-cyclodextrin inclusion complexation by means of a supercritical solvent in the presence of auxiliary agents. J. Supercrit. Fluids, 57(3): 259-266.

4. Doijad, R. C., Kanakal, M. M., \&Manvi, F. V. (2007). Effect of processing variables on dissolution and solubility of piroxicam: hydroxypropyl- $\beta$-cyclodextrin inclusion complexes. Indian J. Pharma. Sci, 69(2): 323-323. 
5. Ribeiro, A., Figueiras, A., Santos, D., Veiga, F. (2008) Preparation and Solid-State Characterization of Inclusion Complexes Formed Between Miconazole and Methyl- $\beta$-Cyclodextrin. AAPS Pharm. Sci. Tech, 9(4): 1102-1109.

6. Ghorab, M. K., Adeyeye, M. C. (2001) Elucidation of solution state complexation in wet-granulated oven-dried ibuprofen and beta-cyclodextrin: FT-IR and 1H-NMR studies. Pharm. Dev. Technol, 6(3): 315-324.

7. Shankarrao, K. A., Mahadeo, G. D., \&Balavantrao, K. P. (2010). Formulation and in-vitro evaluation of orally disintegrating tablets of olanzapine-2-hydroxypropyl- $\beta$-cyclodextrin inclusion complex. Iran. J. Pharma. Res, 9(4): 335-337.

8. Higuchi, T., \& Connors, K. A. (1965). Phase-solubility techniques. Adv. Anal. Chem. Instrum, 4: 117212.

9. Pralhad, T., \&Rajendrakumar, K. (2004). Study of freeze-dried quercetin-cyclodextrin binary systems by DSC, FT-IR, X-ray diffraction and SEM analysis. J. Pharm. Biomed. Anal, 34(2): 333-339.

10. Aigner, Z., Berkesi, O., Farkas, G., \&Szabó-Révész, P. (2012). DSC, X-ray and FTIR studies of a gemfibrozil/dimethyl- $\beta$-cyclodextrin inclusion complex produced by co-grinding. J. Pharm. Biomed. Anal, 57 (1): 62-67.

11. Basan, H., Göğer, N. G., Ertaş, N., \&Orbey, M. T. (2001). Quantitative determination of piroxicam in a new formulation (piroxicam- $\beta$-cyclodextrin) by derivative UV spectrophotometric method and HPLC. J. Pharm. Biomed. Anal, 26(2): 171-178.

12. Archer, M.A., Kumadoh, D., Yeboah, G.N., Kyene, M.O., Kumatia, E.K., Antwi, S. and Appiah, A.A., 2020. Formulation and evaluation of capsules containing extracts of Cassia sieberiana for improved therapeutic outcome. Scientific African, 10: p.e00609.

13. Yao, Y., Xie, Y., Hong, C., Li, G., Shen, H., \& Ji, G. (2014). Development of a myricetin/hydroxypropyl$\beta$-cyclodextrin inclusion complex: Preparation, characterization, and evaluation. Carbohydrate Polymers, 110: 329-337.

14. Setti, M.V. and Ratna, J.V., 2014. Preparation and evaluation of controlled release tablets of carvedilol. Asian J. Pharm, 3(3): 252-256.

15. British Pharmacopoeia Commission. (2008). British pharmacopoeia2009. Stationery Office (UK).

16. Pujara, N. D., \&amp; Parmar, R. B. (2013). Formulation and evaluation of hard gelatin capsule of losartan potassium. Inventi Rapid, 2: 1-4.

17. Nagabhushanam, M. V. (2010). Formulation studies on cyclodextrin complexes of piroxicam. Rasayan J. Chem, 3(2): 314-320. 